\title{
Erratum to: Increase of brain endocannabinoid anandamide levels by FAAH inhibition and alcohol abuse behaviours in the rat
}

\author{
Andrea Cippitelli • Nazzareno Cannella • Simone Braconi - Andrea Duranti • \\ Andrea Tontini - Ainhoa Bilbao • Fernando Rodríguez DeFonseca • Daniele Piomelli • \\ Roberto Ciccocioppo
}

Published online: 17 May 2011

(C) Springer-Verlag 2011

\section{Erratum to: Psychopharmacology}

\section{DOI 10.1007/s00213-008-1104-0}

The affiliations for one of the authors, Daniele Piomelli, were incorrectly given. They should read:

\section{Piomelli}

Departments of Pharmacology and Biological Chemistry, University of California, Irvine, Irvine,

California 92697-4625

\section{Piomelli}

Unit of Drug Discovery and Development, Italian Institute of Technology, 16163 Genoa, Italy

The online version of the original article can be found at http:// doi.org/10.1007/s00213-008-1104-0.

\footnotetext{
A. Cippitelli $\cdot$ N. Cannella $\cdot$ S. Braconi $\cdot$ R. Ciccocioppo $(\triangle)$ Department of Experimental Medicine and Public Health, University of Camerino, Via Madonna delle Carceri, 62032 Camerino, Italy

e-mail: roberto.ciccocioppo@unicam.it

A. Duranti $\cdot$ A. Tontini

Institute of Medicinal Chemistry,

University of Urbino "Carlo Bo", Piazza del Rinascimento 6,

61029 Urbino, Italy

A. Bilbao · F. R. DeFonseca

Fundación IMABIS, Hospital Carlos Haya de Málaga,

Avenida Carlos Haya 82,

29010 Malaga, Spain

D. Piomelli

Departments of Pharmacology and Biological Chemistry,

University of California, Irvine, Irvine, CA 92697-4625, USA

D. Piomelli

Unit of Drug Discovery and Development,

Italian Institute of Technology, 16163 Genoa, Italy
} 